\title{
The Emerging Innovation Ecosystems and "Valley of Death": Towards the Combination of Entrepreneurial and Institutional Approaches
}

\author{
${ }^{1}$ Vytautas Magnus University \\ Daukanto st. 28, 44246, Kaunas, Lithuania \\ E-mail.giedrius.jucevicius@vdu.lt \\ ${ }^{2,3}$ Kaunas University of Technology \\ Gedimino st. 50, 44029, Kaunas, Lithuania \\ E-mail.rita.juceviciene@ktu.lt,vaidas.gaidelys@ktu.lt \\ ${ }^{4}$ Budapest University of Technology and Economics \\ 1111 Budapest, Muegyetem 3, Hungary \\ E-mail.kalman.a@eik.bme.hu \\ cross $^{\text {ref }}$ http://dx.doi.org/10.5755/j01.ee.27.4.14403
}

Giedrius Jucevicius ${ }^{1}$, Rita Juceviciene ${ }^{2}$, Vaidas Gaidelys ${ }^{3}$, Aniko Kalman ${ }^{4}$

\begin{abstract}
This paper provides the discussion regarding the nature, origins and diversity of innovation ecosystems with particular emphasis on the context of the emerging economies and "smart specialisation" paradigm of regional development. Bridging the gap between the research economy and commercial economy ("Valley of Death") remains one of the key concerns of the mature and institutionalised innovation ecosystems. However, many of the emerging innovation ecosystems still suffer from underdeveloped institutional frameworks and fragmented ties of actors, which is a more pronounced challenge than "Valley of Death". It is important to take into consideration the specific needs of different innovation ecosystems in the context of the current EU innovation and regional policies (recently synergised under "smart specialization"). The development of sustainable innovation ecosystem requires a different mentality than the traditional institutional-regulatory approach adopted in the context of national innovation systems. It means the search for delicate balance between the supplyside and demand-side interventions, public and private, openness and ownership, long-term and short-term perspectives, quality of elements and their relationships, adequate policy actions and smooth functioning of the "invisible hand". The emerging innovation ecosystems need to complement their entrepreneurial profiles with stronger institutional frameworks and innovation support mechanisms, whereas the mature institutionalised innovation ecosystems should not over-rely on institutional, supply-side solutions, but strengthen the entrepreneurial culture that is even more critical to innovation success.
\end{abstract}

Keywords: Innovation Ecosystems, Valley Of Death, Emerging Economies, Institutional Approach, Entrepreneurial Approach.

\section{Introduction}

The innovation ecosystems has emerged as a dominant concept in the recent academic discourse in the field of innovation management (Adner \& Kapoor, 2010; Zahra \& Nambisan, 2012; Clarysse et al., 2014; Frenkel \& Maital, 2014; Makinen \& Dedehayir, 2014; Ozer \& Zhang; 2015; Adner \& Kapoor, 2016). It has almost displaced the traditional innovation systems approach (Lundvall \& Johnson, 1992; Cooke et al., 1998), and builds upon the extensive literature in the field of innovation-related networks (Capaldo, 2007; Soh, 2010; Baum et al., 2014; Kapoor \& Mahn, 2013; Patel et al., 2014; McIntyre \& Srinivasan, 2016). Innovation ecosystem is a complex network of interactions between the actors from industry, government and academia that underlies the innovative activities and performance in the area. Deborah J. Jackson, a researcher at National Science Foundation (NSF) and originator of the concept regards the innovation ecosystem as consisting of two key independent, yet related subsystems: „research economy“, which is a product of academic research and industry-academia cooperation, and „commercial economy“, which transforms the research outcomes into commercially viable products. The gap that emerges between the two economies is referred to as the "Valley of Death". It is in this "valley" that many innovation-related initiatives are discontinued by the ecosystem actors (especially the investors) due to high need for investment and uncertain market outcomes (Jalonen, 2012).

Overcoming the "Valley of Death" has become a key concern for the EU innovation policy makers who are trying to create the European innovation ecosystem by synergizing the mechanisms of innovation and regional policies in the context of "smart specialization". Most authors who analyse the innovation ecosystems focus on the mature environments, such as - USA, Germany, Switzerland, France or Nordic economies. Although they are far from uniform, these countries/regions possess the established institutions and norms of market coordination underlying the innovation ecosystems. However, many of the emerging economies have a rather limited leverage for building 
competitive innovation ecosystems, especially when participating on equal terms in the same competitive and policy arena (e.g. EU). Research on the emerging innovation ecosystems remains quite limited (e.g. Maharajh \& Kraemer-Mbula, 2010; Mezzourh \& Nakara, 2012; Davidson et al., 2015). It is not quite clear how entrepreneurial and institutional approaches can be combined to achieve functioning innovation ecosystems in the emerging economic environments. This is an important research problem.

The aim of this paper is to provide a discussion on the ways the entrepreneurial and institutional perspectives can be successfully combined in the context of the emerging innovation ecosystems. This question is particularly important in the context of policy debates on "smart specialization" and search for synergies between the EU innovation and regional policy, which offers both opportunities and some threats to the catching-up economies.

The research methods include the analysis of scientific literature and policy documents, as well as analysis of the findings from secondary sources of empirical research. Some empirical findings from the original research (i.e. cross-national surveys) by the authors of the paper are also integrated into the analysis.

First, we discuss the concept of innovation ecosystem and the key underlying elements behind its success. We highlight the main difficulties faced by the emerging innovation ecosystems.

Second, we present the different typologies of national and regional innovation ecosystems, as well as their key "drivers" and "anchors". We look into the different importance of institutional and entrepreneurial factors within these diverse regional/national settings. In the light of these examples, we look at the prevailing profiles of the emerging, "catching-up" innovation systems and distinguish the key opportunities and challenges.

Finally, we analyse the prevailing competitiveness discourse in the context of "smart specialization" (especially on the EU level) and strategies for overcoming the innovation "Valley of Death". We ask the question to what extent the proposed initiatives are favourable to the emerging innovation ecosystems and capable of bridging the growing innovation gap across the European regions. We finalise by looking for the potential combinations of institutional and entrepreneurial approaches in order to build healthy and cohesive innovation ecosystems within Europe that take into account the growth interests of the "latecomers".

\section{Innovation Ecosystems: Foundations of Concept}

The concept of innovation ecosystem has gained popularity over the last decade, but it builds on a long tradition of related theoretical constructs. In 1850's the term "national system" was referring to the institutional mechanisms that had to be systemically applied on the national scale to achieve the economic catch-up with the industrialised nations (e.g. G. F. List used this term in the context of German industrial catch-up with Britain). At the turn of $20^{\text {th }}$ century, Alfred Marshall $(1890 ; 1927)$ gave birth to the concept of "agglomeration" and its positive economic effects on the firms located in close proximity to each other. The later concepts, such as "industrial districts" encompassing the geographically and culturally related inter-firm networks were largely influenced by the Marshallian perspective. Perroux (1961; 1965) combined the insights of A. Marshall and J. Schumpeter's "creative destruction" and claimed that economic growth does not happen in all regions, but is concentrated in the specific "growth poles" focused around the firm(s) or related industries with oligopolistic, or even monopolistic (in a short run) position in the market. Dahmen (1988) introduced a related term "development blocks" as a recipe for Sweden's industrial transformation. Probably the most influential concept in the recent academic research on geography-centred economic development is "clusters" by the American strategic management professor Michael Porter (1990). The classical definition of cluster is "geographic concentrations of interconnected companies, specialized suppliers, service providers, firms in related industries, and associated institutions (e.g. universities, standards agencies, trade associations) in a particular field that compete but also cooperate" (Porter, 2000). The notion of cluster takes into account not only the aspects of geographical proximity of the industry actors, but also their adjacent position in the value chain of industry or product. M. Porter explains the national economic competitiveness through the combination of demand and supply-side factor conditions, and the concentrations of related and supporting industries (i.e. clusters). So in the classical interpretation clusters were regarded as productive economic agglomerations of industry actors. Gradually, the notion of "business cluster" was extended to encompass the "innovative clusters" where productive activities are enhanced by the knowledge transfer and spillovers leading to innovative products and services.

The concept of "innovation ecosystem" owes even more to the innovation-focused research and related concepts. One of them - the concept of "national system of innovation", introduced by Freeman and Lundvall (1988) embraces not only the actors situated along the economic value chain, but also, and especially, a wider context of national actors / institutions involved in the creation, transfer and commercialisation of knowledge (i.e. system of education and training, macroeconomic and regulatory context, factor market conditions, firm's capabilities and networks, research bodies and supporting institutions). In 1990s, Etzkowitz (1993), Etzkowitz and Leydesdorff (1995) introduced the concept of the Triple Helix centred on the university-industry-government relationships. The concept emphasises the switch from Industrial Society (and its focus on industry-government partnership) towards Knowledge Society, and the growing economic importance of universities and research institutions in the production of knowledge. The concept of "regional innovation systems" (Cooke et al., 1998; 2004) regards regions as the locus of innovation by stressing the importance of different types of organizations in regional innovation processes: education and research, knowledge transfer and adaptation, funding and information support.

The Triple Helix Research Group at Stanford University has noticed that substantive body of Triple Helix literature 
can be broadly seen from two main complementary perspectives.

Neo-institutional perspective focuses on various aspects of the university 'third mission' of commercialization of academic research and involvement in socio-economic development, such as forms, stakeholders, drivers, barriers, benefits and impact, university technology transfer and entrepreneurship, contribution to regional development, government policies aimed to strengthen universityindustry links, etc. The authors distinguish three different configurations of power within the Triple Helix: 1) statist configuration where state institutions play the key role in driving and also limiting industrial and academic actors; 2) laissez-faire configuration where industry actors are the prevailing force behind the innovation process, and 3) balanced configuration, where knowledge institutions (universities, research institutes) are in partnership with other system actors, or even take the lead in the innovation process. The latter configuration is usually regarded as the most desirable.

Neo-evolutionary perspective sees the participants of the Triple Helix as co-evolving sub-sets of social systems that interact through networks and organizations, which "reshape institutional arrangements through reflexive subdynamics". Leydesdorff and Etzkowitz (1996, 1998) distinguish two processes of communication and differentiation among the different actors of innovation system: a functional process of interaction between science and markets, and institutional process, between private and public control at the level of universities, industries and government, which allow various degrees of selective mutual adjustment (Leydesdorff and Etzkowitz, 1996, 1998)

As already mentioned, the concept of "innovation ecosystem" owes a lot to many of the above mentioned concepts and approaches. However, it also in a way challenges the traditional (neo-) institutional approach to innovation systems (e.g. NIS approach) and puts greater emphasis on the "ecosystem" qualities of complex, selforganizing and emergent innovation processes. So the innovation ecosystems thinking fits more comfortably within neo-evolutionary than neo-institutional approach. From systems thinking perspective, the innovation ecosystems (just like industrial clusters) belong to the category of complex adaptive systems. It means that every innovation ecosystem is unique, historically evolved and embedded in the cultural (and institutional) fabric of the region. Although some innovation ecosystems, such as Silicon Valley, inspire the imitators from all around the world, their specific pattern of emergence is almost impossible to replicate.

The evolutionary nature of innovation ecosystem is revealed through its (not complete) analogy with the biological ecosystems. One of the early proponents of the concept was Deborah J. Jackson (uncited) from National Science Foundation (NSF), who explained the key commonalities and differences between the biological and innovation ecosystem. Biological ecosystem is characterised by the closed loop of energy dynamics among the living resources, habitats and residents of the area (i.e. actors and their environment) with a functional goal to maintain an equilibrium sustaining state. Innovation ecosystem, on the other hand, reflects the economic dynamics ,between actors and entities whose functional goal is to enable technology and innovation. According to D. J. Jackson, the actors of innovation ecosystem include the material resources (funds, equipment, facilities) and human capital (researchers, entrepreneurs, skilled employees, etc.) that are part of institutional entities of the ecosystem (universities, research organizations, business firms, venture capitalists and business angels).

Probably the most critical aspect of innovation ecosystem is that it comprises two different, but inter-related economies: research economy and commercial economy. Research economy is focused on production of new knowledge and technologies, whereas commercial economy is responsible for the practical implementation in the marketplace. The first is often related to pubic (and private) initiatives and investment, whereas the success of the latter lies with the private sector. Successful functioning of innovation ecosystem depends on management of various tensions and contradictions. On one hand, the incentives behind the research economy have to be different than the incentives driving the commercial economy. On the other hand, D. J. Jackson notices that, ,resources available to the research economy are coupled to the resources generated by the commercial economy, usually as some fraction of the profits in the commercial economy".

Frenkel and Maital (2014) notice that every innovation ecosystem contains an inherent paradox. The short-run driven commercial economy must be tightly linked to the long-run-driven research economy, but at the same time insulated from it. The authors also notice that the functioning of innovation ecosystems depends on the quality of its elements, as well as on the quality of their relationships on the system level: "innovation is the result of the complex interaction among a large number of separate elements, involving industry, government and academe (...); its success depends on how well the system as a whole functions, and how well each individual element in the ecosystem supports the other elements". So to achieve a smoothly functioning innovation ecosystem it is not enough to build the "right" elements (i.e. actors, institutions, resources), but they need to develop adequate productive linkages and certain culture of coordination. The very nature of ecosystem implies that these linkages cannot be ,forced upon", but should rather emerge gradually, on the basis of self-organization and moderated interactions. The development of innovation ecosystem cannot be approached from the perspective of linear logic. More often than not, such interventions produce unintended effects and consequences. For example, strapping the public research funds available to universities is often presented by policy makers as an incentive to promote the linkages between basic research and market demand (i.e. private investors into research), but in reality it damages the quality and quantity of research output and undermines the performance of innovation ecosystem in the long run (Frenkel \& Maital, 2014).

Therefore, the development of sustainable innovation ecosystem requires a different mentality than the traditional institutional-regulatory approach usually adopted in the context of national innovation systems. It implies a continuous quest for a delicate balance between the supply- 
side and demand-side interventions, public and private, openness and ownership, long-term and short-term perspectives, quality of elements and their relationships, adequate policy actions and smooth functioning of the "invisible hand".

\section{"Stocks" and "Flows" of Innovation Ecosystems: Factors Behind National Diversity}

Although the innovation ecosystem is far from uniform concept and there are no "one size fits all" solutions in this regard, there are certain common parameters underlie every functioning innovation ecosystem, such as Silicon Valley or Third Italy (no matter how big their differences). One of the authors of this paper (Jucevicius, 2007) has analysed the different innovative regions throughout the history and found common success factors, such as relatively strong middle class, equality of opportunity (i.e. flat social hierarchies), functioning market mechanisms and social networks, active role of vocational training institutions, openness and entrepreneurship, dynamic funding and technological base. Of course, the actual expression of these parameters in diverse cultural-institutional contexts (e.g. US, Japan or Germany) was quite different. No innovation ecosystem is exactly the same on all parameters, but represents the different combinations of factors.

Frenkel and Maital (2014) have constructed their crossnational research of different innovation ecosystems on the basis of two underlying concepts / parameters:

- "Quality anchors" (or "stocks" in systems theory), which represent the key strengths / core competences in the region / nation, on which innovation is being built (e.g. specialised skills, technological infrastructure, specific industrial traditions, etc.)

- "Processes and trends" (or "flows" in systems theory), which are the processes that enable countries / regions overcome the strategic weaknesses and constraints (e.g. educational programmes, regulatory practices, tax incentives, innovation funding schemes, etc.)

The authors have conducted in-depth expert interviews from different innovation ecosystems and revealed their cross-national diversity. They also identified three different categories of innovation drivers, those that were:

1) shared with all other countries;

2) shared with some other countries, and

3) shared with no other countries.

The analysis covered the national innovation ecosystems of Israel, Poland, Germany, France, Spain, Singapore and some others. The most shared "anchors" across the innovation ecosystems are scientific and technological infrastructure, human capital, governance direction, transparency and accountability, technological structure that support innovation, and individual energy of entrepreneurs who drive the innovation ecosystem. The more advanced the innovation ecosystem, the more complex its composition in terms of actors, institutions and their relationships. The "emerging" economies (e.g. Poland) have more simple ecosystems (due to young actors and their fragmented relationships).
At this stage, we would like to present some examples of specific "anchors" and "processes" found in different national settings.

The Israeli innovation ecosystem rests on some unique cultural and institutional factors: strong scientific and educational infrastructure (related to government programmes, publically funded research universities and private-public sector cooperation), competitive structure of economy (large companies and dominance of some 20 families in business), economic institutions (government support to military R\&D and further commercial applications) and entrepreneurship (skills being taught from the early age), "out-of-the-box thinking", culture of empowerment and diversity of human resources. The last three anchors are particularly unique to the Israeli culture and innovation ecosystem in international context. There are strong ties between the cultural factors and supply- and demand-driven processes, between the scientific base and entrepreneurship infrastructure.

The German innovation ecosystem relies on such key anchors as high-level technological capabilities (technological leadership in many industries), market structure (export strengths, strong SMEs and middle hightech), pro-innovation culture, availability human capital (specialised skills, public funded basic and applied research), governance and institutional structure (institutional stability, associations, decentralized support programmes) and external effect (few natural resources, central location). Despite the strong institutionalisation and inter-connectedness, the main processes in German innovation ecosystem are demand-driven. It has profited from its complementarity to the Chinese manufacturing system, strategic agility of German firms and flexible reorientation of exports on the global scale. Institutional stability is well coupled with entrepreneurial agility oh specialised high technology firms (though rigidity of government bureaucracy remains a constraining factor).

The French innovation ecosystem relies a lot on the role of the government, its budget, policy, regulations, public procurement, state-coordinated education system and demand-side policies (e.g. choice of "lead markets" by the government). The French system is dominated by large firms and scores low on most indicators related to entrepreneurial energy and start-up activity (most entrepreneurial activities are taking place within large companies). The findings show some very strong technological skills located in the French innovation ecosystem, but which are not adequately translated into commercial products. The high level technical competence found in French research universities is not fully integrated into the innovation ecosystem with the industry actors.

The Polish innovation ecosystem falls within the category of "emerging" ecosystems, characterised by young actors, low connectivity and loose ties on the system level. What is quite characteristic to the early-stage innovation environments is relatively weak institutional factors and much greater role played by the entrepreneurial, demandside interactions. In Polish case, two demand-side processes are particularly important: private sector attractiveness and desire for technological independence among the local population. The key anchors of the Polish innovation ecosystem are also more of social-cultural (rather than 
institutional) nature. There is a strong culture of entrepreneurship (tendency to tinker things, go against patterns and take risks), human capital infrastructure (good overall education, creativity, trained young professionals by MNCs), culture of empowerment (desire for success, independence of thinking and acting). Polish innovation ecosystem also benefits from its external integration, such as building on the linkages to the neighbouring German economic system and the availability of the EU resources that are being invested in strengthening the local innovative capacity.

The above mentioned examples show the different building blocks and key success factors behind the national innovation ecosystems that lead to (and are also result of) different industrial specialization. Some of these ecosystems are dominated by the supply-side factor and strong public / institutional infrastructure (e.g. France). Others have more pronounced elements on the demand-side and "soft" micro-level entrepreneurial factors (e.g. Poland). Then there are ecosystems that manage to combine the supply-side and demand-side, public and private, macro and micro factors (e.g. Germany, Israel) and as a result usually show higher innovation performance.

However, it is quite challenging to address the needs of concept of smart specialization was initiated in 2008 by a group of researchers led by Dominique Foray (Foray et al., 2009). It is based on the assumption that, in order to be used productively and to achieve systemic effects, the resources and policy interventions must be specifically targeted to reinforce the existing regional economic (and innovation) ecosystems. It means filling the necessary gaps and strengthening the weak links in the economic ecosystems in order to make them more innovative and productive (i.e. to achieve specialization while at the same time avoiding the lock-in effect). Smart specialization differs from traditional interventionist approaches in that it admits the central role of entrepreneur in value creation, and seeks to complement the market trends rather than shape or replace them. On the other hand, it does not fully adopt the traditional laissezfaire approach in that it seeks to provide the systemic institutional support to micro-level actions of entrepreneurs, which should be complementary to the existing regional strengths (i.e. traditions, resources, human, social and institutional capital).

One of the key challenges that every innovation ecosystem has to address is bridging the technological "Valley of Death" (see Figure 1). The Valley of Death means the gap that emerges between the research economy

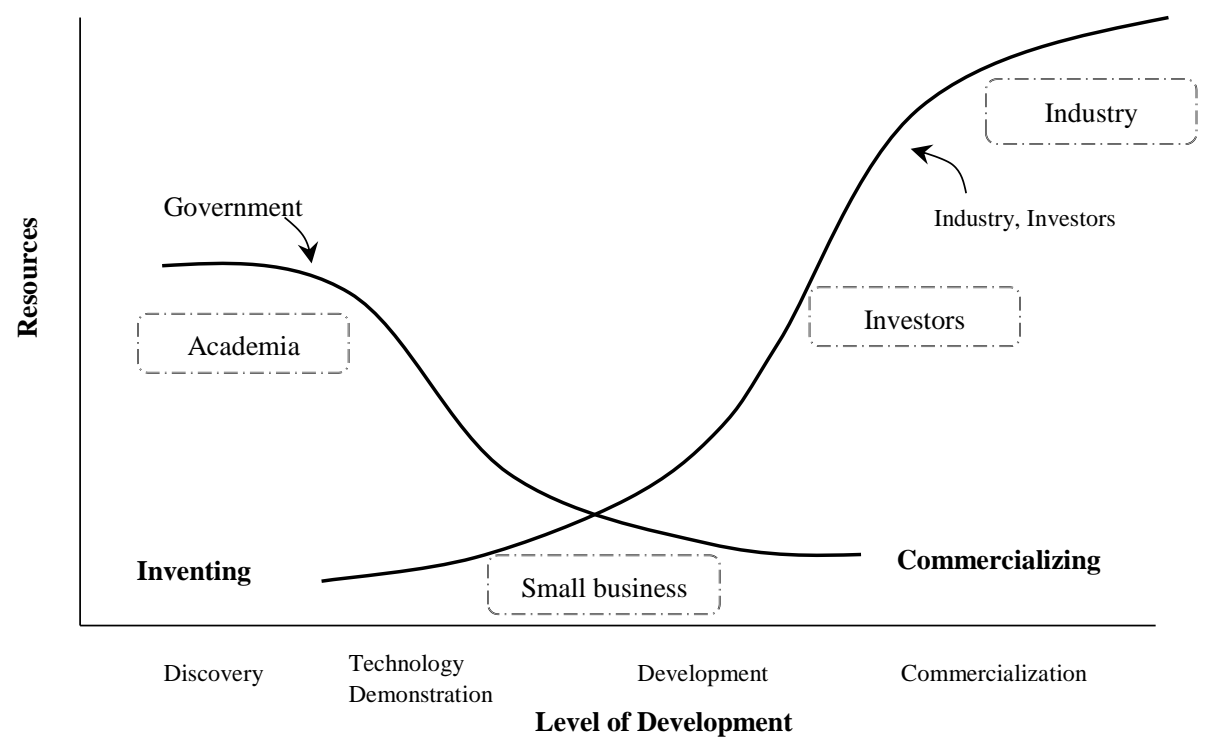

Figure 1. Traditional "Valley of Death" in Mature Institutional Innovation Ecosystems

the different innovation ecosystems, especially on the level of the EU. In the next chapter, we discuss the challenges in building the European innovation ecosystem by taking into consideration the existing diversity and conflicting/complementary policy objectives. We argue that institutional and entrepreneurial approaches need to be synergised by sensitively taking into account the specificity of diverse national innovation ecosystems.

\section{Towards "Smartly Specialised" European Innovation Ecosystem: Bridging Institutional and Entrepreneurial Perspectives}

The current debates surrounding the European innovation ecosystem take place in the context of the developmental paradigm of "smart specialization". The and commercial economy, between the technologies and ideas that emerge from publically funded research environment and the practical implementation in the marketplace in the form of commercially viable products and services. According to D. J. Jackson, this is a fundamental dilemma that every innovation ecosystem has to address: how to turn the breakthroughs of R\&D into products that lead to profits?

The Valley of Death is associated with the most risky stage in the innovation process, which is probably the key reason behind the emergence of the "valley" itself. It means that, on one hand, governments concentrate their investment into fundamental research (curve on the left). On the other hand, industry invest substantial resources into direct product development and commercialization (curve on the right). However, the early stage of product development, 
which is based on technology demonstration, customer validation, co-piloting and prototyping (on a larger scale than in the laboratory environment, but not yet on the industrial scale). This stage calls for the allocation of substantial resources with unclear return on investment (ROI) and a high rate of failure (often nine out of ten investment projects fail). It is a strong discouraging factor for private investors that opt out for more secure investment alternatives and often abandon the innovation-related projects.

Even the healthiest of innovation ecosystems are in no position to fully eliminate the "valley of death". However, they contain the supply- and demand-side solutions that minimize the negative effects of such disruption in resource distribution. In fact, it means pushing both curves towards each other so that the effects of "valley of death" are minimized (i.e. resource allocation becomes relatively balanced across all stages of innovation development). It means that resources invested in the research economy are later retrieved in the commercial economy.

Productive innovation ecosystems positively influence the ways entrepreneurs/investors approach the uncertainty and risk. They enable the entrepreneurs "to handle failures in a way that encourages terminating losing investment early" (i.e. "fail fast") and "to efficiently recover and recycle resources that are released upon the failure of individual enterprises" (Jackson, 2011). They also promote the culture of risk taking so that individual entrepreneurs are more likely to place greater bets in an uncertain technological and business environment. Nowhere is the "redemption narrative" (i.e. achieving ultimate success by passing through multiple failures) as prevalent as in the innovation ecosystem of Silicon Valley (McGowan, 2016).

The innovation ecosystems try to keep the fast growing companies within the native ecosystem, as well as to engage the marginal and moderate growth firms that are not profitable enough by the venture capital standards (Samila \& Sorenson, 2010). The presence of such "middle class" is important and serves as a habitat for the forthcoming champions.

The public infrastructure of innovation ecosystem for piloting, validation, prototyping, scaling-up and demonstration of new technologies / ideas also plays an important part in overcoming the "valley of death". Such infrastructure helps to spread and reduce the individual risk of enterprises, lowers the entry costs to the new players. As a result, the potential investors are more eager to participate in innovation-related undertakings as the prospects of profitability (as a factor of increased productivity and aggregated investment in all - successful and failed ventures) are increased.

The European Commission has set the aim to create the European innovation ecosystem that enable close-to-market innovation in 6 Key Enabling Technologies (KETs): advanced materials, nanotechnology, micro- and nanoelectronics, industrial biotechnology, photonics and advanced manufacturing technology. If surrounded by healthy innovation ecosystem, such high technologies can become strong drivers behind disruptive innovations

\footnotetext{
${ }^{1}$ Report „Industrial Technologies for Regional Growth“ Proceeding from the EC workshop, Brussels, 12 April, 2016, prepared by Giedrius Jucevicius.
}

(Christensen, 1997; Dedehayir et al., 2014; Dedehayir \& Seppanen, 2015). KETs are likely to define the future of European (and global) manufacturing, but they are particularly sensitive to the "Valley of Death" due to their novelty, uncertain commercial applications and high level of investment required during the development and precommercialization stage. For example, during the pilot production and demonstration stage, the costs increase five times compared to earlier stages, and many firms are not prepared to bear this burden alone, without partners or government support.

As far as smart specialization is concerned, two thirds of EU regions have identified various KETs as part of their smart specialization strategies (3S). As a result, though smart specialization, the development of key enabling technologies has been linked not only to the traditional mechanisms and programmes of EU innovation policy, but also the EU regional development and structural funds.

One of the authors of this paper was the moderator of high-level expert group discussion regarding the EU-level strategies for KET-focused smart specialization. Some most important remarks from the focus group discussion are presented here ${ }^{1}$

In theory, the creation of European innovation ecosystem in the field of KET, while at the same time seeking regional cohesion is a commendable aim, but in practice, it faces quite a few challenges.

First, the last decade has seen the growing gap across the innovation-related performance among the EU countries and regions. The most productive innovation ecosystems are concentrated in the regions with strongest agglomerations of economic and knowledge activities. The differences among innovating vs. non-innovating regions are increasing rather than decreasing over time. The development and commercialization of KETs depend on particularly high level of expertise, which is clustered in the lead manufacturing areas of the EU. It means that despite the fact that $2 / 3$ of all EU regions declare KET as part of their smart specialization, the majority of investment goes into the most economically advanced areas. The latecomer EU regions can hardly compete for the innovation policy related funding on the EU level.

Second, there are several proposed solutions to the existing problem of limited funds going to the most developed regions. One of the proposals is to establish the pan-European infrastructure for pilot production and demonstration in KETs that no matter its location (mostly advanced economic areas) is open to potential partners from all around EU. Another potential solution is extending the limited funding available under the instruments of innovation policy (Horizon 2020) to the instruments of regional development (i.e. EU structural funds). The concept of smart specialization is sufficiently inclusive to cover both the aspects of $\mathrm{R} \& \mathrm{D}$ and regional development policy.

However, in this context, the emerging innovation ecosystems (e.g. in Eastern and Southern parts of the EU) face several potential difficulties. The first problem is more technical and related to the nature of funding mechanisms. 
The second problem is more conceptual and reflects the fundamental needs of the emerging innovation ecosystem.

Regarding the first technical issue, the structural funds are traditionally used on the regional municipal level for the purposes of building physical infrastructure and other related activities. The municipalities have very limited experience as actors of the innovation ecosystem dealing with the innovation-related funding, especially in the emerging economies. Therefore, they may not be in a position to have the necessary competence and to make use of the innovation policy instruments (e.g. Horizon 2020). On contrary, the actors from relatively developed innovation ecosystems are more likely to access and male use of the structural funds, traditionally reserved for regional development. Paradoxically, such situation may result in further increasing divergence across the EU regions. systems" (Cooke et al., 2004), where public bodies play a key role in shaping the structure and incentives of the innovation ecosystem. It is in such institutionalized systems that the problem of commercialization of highly expensive public research outputs ("valley of death") is especially pronounced.

The emerging innovation ecosystems, on the other hand, have both limited resources for investment into basic research and, quite naturally, limited private resources that are invested into large scale commercialization of innovative products (that have little chance to emerge due to insufficient powers of both technology-push and marketpull). Somewhat paradoxically, due to underdeveloped nature of innovation ecosystem, the "valley of death" in the emerging economies is not so deep (see Figure 2). On the other hand, it will grow deeper once more resources are allocated to the basic research.

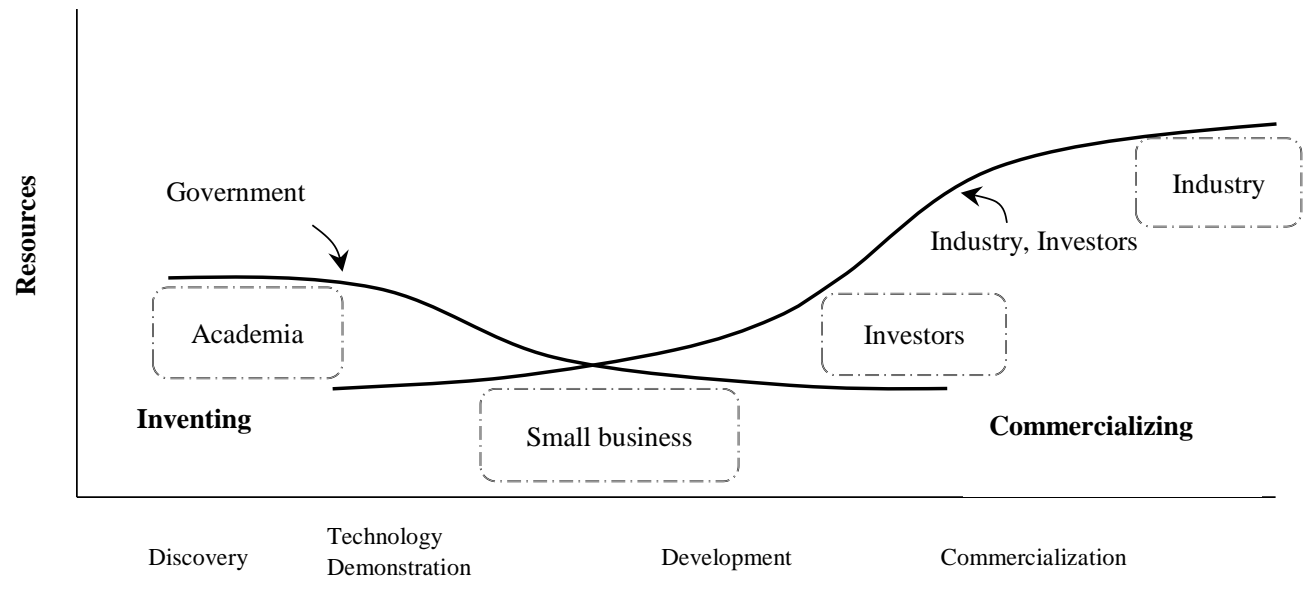

Level of Development

Figure 2. Flat "Valley of Death" in the Emerging Innovation Ecosystems

The second issue is more conceptual and is related to the specific needs of emerging innovation ecosystems. As already mentioned, many young innovation ecosystems do not have a solid institutional framework and established innovation infrastructure (i.e. supply-side conditions). In most cases, they are more likely to be characterized as "entrepreneurial regional innovation systems" (Cooke et al., 2004) which means that their innovativeness depends on many fragmented micro-level entrepreneurial initiatives and high energy for achievement (e.g. as indicated above in the case of Poland), but they are not systemically sustained by institutions and supporting organizations. For example, Arocena and Sutz (2000) notice that in Latin American innovation systems, the micro-innovative strengths exist, but remain isolated and encapsulated. It means that the emerging ecosystems often have quite capable individual actors, but lack the collective, system-level capabilities. They suffer from underdeveloped public and private funding, insufficiently developed general (or industryspecific) innovation infrastructure and loose ties among the ecosystem actors. In other words, the emerging "entrepreneurial" innovation ecosystems are faced with quite different challenges than the mature "institutional" ecosystems, which often dominate the EU discourse on innovation policy. For example, France and its regions represent a typical case of "institutional regional innovation

\section{Conclusions}

The development of "emerging" innovation ecosystems calls for a reassessment of the innovation policy (and regional policy) priorities on the EU level, especially with regard to instruments behind the support for "smart specialization". At least several aspects need to be taken into consideration.

First, should the EU achieve a higher level of regional cohesion on the basis of smart specialization, the innovation policy has to consider the specific needs of the emerging innovation ecosystems (while at the same time addressing the key concerns of leading industrial regions).

Second, one should not overlie on the institutionalist approach (despite its advantages) in building the innovation ecosystem within Europe. The ultimate success of innovative initiatives finally rests with the entrepreneurial mindset, motivation and capabilities. So in spite of obvious importance of investing into the innovation support infrastructure, one must continue focusing on building stronger entrepreneurial culture and patterns of behaviour. This is one area where actors in the "emerging" ecosystems are even capable of showing some good practices to their more institutionalised partners.

Finally, it is important to keep in mind that the strength of European innovation ecosystem lies not in uniformity, 
but in its diversity. It is not quite realistic to expect that the current two third of EU regions will remain "smartly specialized" in key enabling technologies. One should avoid building the innovation strategies around the technological "fashions", which unfortunately is often the case. The emerging innovation ecosystems have to continuously refine their smart specialization strategies to discover some deeper profiles and more original competitive identity (maybe even inside KETs). They also need to gradually complement their existing entrepreneurial strengths with the emerging institutions, resources and collective learning capabilities.

\section{Acknowledgements}

The paper was prepared with the support of the Research Council of Lithuania under the research project "Enabling the selforganization in contemporary innovation ecosystems: perspective of latecomer economy" (MIP-15601).

\section{References}

Adner, R., \& Kapoor, R. (2010). Value Creation in Innovation Ecosystems: How the Structure of Technological Interdependence Affects Firm Performance in New Technology Generations. Strategic Management Journal, 31, 306-333. http://dx.doi.org/10.1002/smj.821

Adner, R., \& Kapoor, R. (2010). Innovation ecosystems and the pace of substitution: Re-examining technology S-curves. Strategic Management Journal, 37, 625-648. http://dx.doi.org/10.1002/smj.2363

Arocena, R., \& Sutz, J. (2000) Looking at National Systems of Innovation from the South, Industry and Innovation, 7(1), 55-75. http://dx.doi.org/10.1080/713670247

Baum, J. A. C., Cowan, R., \& Jonard, N. (2014). Does evidence of network effects on firm performance in pooled crosssection support prescriptions for network strategy? Strategic Management Journal, 35, $652-667$. http://dx.doi.org/10.1002/smj.2133

Capaldo, A. (2007). Network structure and innovation: The leveraging of a dual network as a distinctive relational capability. Strategic Management Journal, 28, 585-608. http://dx.doi.org/10.1002/smj.621

Christensen, C. M. (1997). The innovator's dilemma: when new technologies cause great firms to fail. Harvard Business School Press, Boston, Massachusetts.

Clarysse, B., Wright, M., Bruneel, J., \& Mahajan, A. (2014). Creating Value in Ecosystems: Crossing the chasm between knowledge and business ecosystems. Research Policy, http://dx.doi.org/10.1016/j.respol.2014.04.014

Cooke, P. (1998) Introduction: origins of the concept. In H. Braczyk, P. Cooke \& M. Heidenreich (Eds.). Regional innovation systems, London: UCL Press, 2-25. http://dx.doi.org/10.1007/978-1-4471-3985-0_1

Cooke, P., Heidenreich, M., \& Braczyk, H. J. (2004). Regional innovation systems. London and New York: Routhledge.

Dahmen, E (1988). Development blocks in industrial economics. The Scandinavian Economic History Review 36(1), 314. http://dx.doi.org/10.1080/03585522.1988.10408102

Davidson, S., Harmer, M., \& Marshall, A. (2015). Strategies for creating and capturing value in the emerging ecosystem economy. Strategy \& Leadership, 43(2), 2-10. http://dx.doi.org/10.1108/SL-01-2015-0003

Dedehayir, O., Nokelainen, T., \& Makinen, S. J. (2014). Disruptive innovations in Complex Product Systems industries: A case study. Journal of Engineering and Technology Management, 33, $174-192$. http://dx.doi.org/10.1016/j.jengtecman.2014.06.002

Dedehayir, O., \& Seppanen, M. (2015). Birth and Expansion of Innovation Ecosystems: A Case Study of Copper Production. Journal of Technology Management \& Innovation, 10(1), 145-153. http://dx.doi.org/10.4067/S071827242015000200010

Etzkowitz, H. (1993). Technology transfer: The second academic revolution. Technology Access Report 6, 7-9.

Etzkowitz, H., \& Leydesdorff, L. (1995). The Triple Helix: University - Industry - Government Relations: A Laboratory for Knowledge - Based Economic Development. EASST Review 14, 14-19.

European Commission (2015). Key Enabling Technologies (KETs) Observatory. Second report, December 2015. Available from internet: https://ec.europa.eu/growth/tools-databases/ketstools/sites/default/files/library/kets_observatory_second_report.pdf

European Commission. (2015). Pilot Production in Key Enabling Technologies. Crossing the Valley of Death and boosting the industrial deployment of Key Enabling Technologies in Europe. Available from internet: http://www.mkpl.eu/fileadmin/site/final/mKETs_brochure_web.pdf

Foray, D., David, P. A., \& Hall, B. (2009). Smart Specialisation. From Academic Idea to Political Instrument, the Surprising Career of a Concept and the Difficulties Involved in its Implementation. MTEI Working Paper.

Foray, D., David, P. A., \& Hall, B. (2009). Smart Specialisation - The Concept, Knowledge Economists Policy Brief no. 9, June, 2009. 
Freeman, C., \& Lundvall, B. A. (1988): Small Countries Facing the Technological Revolution, Pinter, London.

Frenkel, A., \& Maital, S. (2014). Mapping National Innovation Ecosystems. Foundations for the Policy Consensus. Edward Elgar, Cheltenham, UK, Northampton, MA, USA. http://dx.doi.org/10.4337/9781782546818

Jackson, DJ. (2011). What is an Innovation Ecosystem? National Science Foundation, Arlington, VA.

Jalonen, H. (2012). The uncertainty of innovation: a systematic review of the literature, Journal of Management Research, $4(1), 1-47$.

Jucevicius, G. (2007). Inovatyvus miestai ir regionai. Kaunas. Technologija

Jucevicius, G., \& Maital, S. (2015). National Strategies of Smart Development: Turning Constraints into Growth Opportunities. In R. Jucevicius, J. Bruneckiene \& G-B von Carlsburg (Eds.) International Practices of Smart Development. Peter Lang Edition, 13-38

Kapoor, R., \& Mahn, J. (2013). Coordinating and competing in ecosystems: How organizational forms shape new technology investments. Strategic Management Journal, 34, 274-296. http://dx.doi.org/10.1002/smj.2010

Leydesdorff, L., \& Etzkowitz, H. (1996). Emergence of a Triple Helix of University - Industry - Government Relations. Science and Public Policy 23, 279-286.

Leydesdorff, L., \& Etzkowitz, H., (1998). The triple helix as a model for innovation studies. Science and Public Policy 25, 195-203.

Maharajh, R., \& Kraemer-Mbula E. (2010). Innovation Strategies in Developing Countries. In E. Kraemer-Mbula and W. Wamae (Eds.), Innovation and the Development Agenda, OECD Publishing.

Makinen, S., \& Dedehayir, O. (2014). Business Ecosystems' Evolution - An Ecosystem Clockspeed Perspective. In R. Adner, J. E. Oxley \& B. S. Silverman (Eds.) Collaboration and Competition in Business Ecosystems (Advances in Strategic Management, Vol. 30) Emerald Group Publishing Limited, 99-125.

Marshall, A. (1890/1927). Principles of Economics. London: Macmillan \& Co.

McGowan. (2016). Silicon phoenix. A gifted child, an adventure, a dark time, and then ... a pivot? How Silicon Valley rewrote America's redemption narrative. Available from internet: https://aeon.co/essays/how-silicon-valley-rewroteamerica-s-redemption-narrative

McIntyre, D. P., \&Srinivasan, A. (2016). Networks, platforms, and strategy: emerging views and next steps. Strategic Management Journal (accepted manuscript online, 14 Oct, 2016).

Mezzourh, S., \& Nakara, W. A. (2012). New Business Ecosystems and Innovation Strategic Choices in SMEs. The Business Review, 20(2), 176-182.

Ozer, M., \& Zhang, W. (2015). The effects of geographic and network ties on exploitative and exploratory product innovation. Strategic Management Journal, 36(7), 1105-1114. http://dx.doi.org/10.1002/smj.2263

Patel, P. C., Fernhaber, S. A., McDougall-Covin, P. P., \& van der Have, R. P. (2014). Beating competitors to international markets: The value of geographically balanced networks for innovation. Strategic Management Journal, 35, 691711. http://dx.doi.org/10.1002/smj.2114

Perroux, F. (1961). L'Economie du XX siècle. Paris. Presses Universitaires de France.

Perroux, F. (1965). La Pensee economique de Joseph Schumpeter: les dynamiques du capitalisme. Geneva: Doz.

Porter, M. (1990). The Competitive advantage of nations. New York: Free Press. http://dx.doi.org/10.1007/978-1-34911336-1

Samila, S., \& Sorenson, O. (2010). Venture capital as a catalyst to commercialization. Research Policy, 39(10), 13481360. http://dx.doi.org/10.1016/j.respol.2010.08.006

Soh, P. H. (2010). Network patterns and competitive advantage before the emergence of a dominant design. Strategic Management Journal, 31, 438-461. http://dx.doi.org/10.1002/smj.819

The article has been reviewed.

Received in May, 2016; accepted in October, 2016. 